\title{
O mausoléu de Augusto e a Apocolocintose de Sêneca
}

\author{
INGEBORG BRAREN \\ Departamento de Letras Clássicas e Vernáculas \\ Universidade de São Paulo
}

\begin{abstract}
RESUMO: Augusto construiu para si e seus familiares um mausoléu, a fim de que seus restos mortais recebessem assim as devidas honras fúnebres. Entre as heranças que deixou, estava o modelo político de soberano, que se perpetuou junto com o Império Romano. Sua lembrança perdurou, e seu mausoléu ainda existe. Ao contrário, a morte do imperador Cláudio, como é tratada na Apocolocintose de Sêneca, deixa como exemplo, um "herói", morto, cuja atuação ocorre em uma trajetória pos-mortem, em um percurso exatamente inverso ao da consecratio, honra de divinização atribuída a alguns imperadores e que the fora conferida, pois na sátira desce do céu para os Infernos.
\end{abstract}

PALAVRAS-CHAVE: Apocolocintose, Sêneca, Imperador Cláudio, Consecratio, Augusto.

A Apocolocintose de Sêneca é uma sátira que trata dos acontecimentos ocorridos no dia 13 de outubro de 54 d.C., dia da morte do imperador Cláudio. Há muitas investigações sobre esta obra. Pode-se reuni-las, de maneira geral, em quatro grupos de investigações de acordo com o tipo de enfoque: 1) estudos sob o prisma político e histórico; 2) estudos sobre a forma (sátira menipéia ou prosimétrica); 3) estudos sobre as intenções que motivaram Sêneca a escrevê-la (intenção pedagógica, vingança pessoal, cancelamento do culto oficial outorgado a Cláudio, desejo de atingir Agripina, etc.); 4) estudos de caráter crítico-literário. Sobre este último aspecto, Rosario Cortés, em seu excelente e pormenorizado trabalho, Teoría de la sátira, Análisis de la Apocolocyntosis de Séneca (Cortés, 1986), comenta os mais recentes trabalhos sobre a obra'.

Talvez seja interessante observar a obra sob um outro ângulo: a morte. O que significa a morte em Roma e o tratamento dado à morte na obra de Sêneca. Se levarmos em consideração o respeito que os romanos tinham por tudo que se relaciona com a morte, este aspecto pode ser de interesse, pois a obra não só focaliza o momento da morte de Cláudio como também o insere, como personagem principal, atuando, depois de morto, no mundo dos mortos.

Ora, desde tempos ancestrais, era costume romano reverenciar seus mortos com uma série de preceitos. O mais importante deles era cumprir todos os ritos fúnebres que variavam conforme as condições sociais e culturais do falecido e de sua família, considerando as circunstâncias em que ocorreu a morte a fim de preservar a memória do morto. A morte era um momento solene. $\mathrm{O}$ respeito aos mortos provinha principalmente de duas causas: uma era a pietas característica da formação do cidadão romano, a outra advinha de uma suspeita de que nem tudo estaria terminado com a morte. Diante da dúvida de que a morte corporal liberaria a alma, dando início a uma outra vida nos Infernos, ou de que havia possibilidades intermediárias (Cic. Tusc. I,9,18), o romano 
preferia prestar os tributos devidos para facilitar a caminhada dos mortos pelo mundo das sombras.

Segundo os antigos a alma não era de todo um espírito. Tinha algo de um sopro diáfano ou de uma sombra impalpável que podia ser vislumbrada (umbra). Não estaria em todos os lugares, mas pairava no mundo visível. As almas preferiam vagar perto de seus túmulos. Caso um corpo não fosse inumado ou incinerado de acordo com os ritos, os espíritos ou os Manes recusavamse a receber sua alma, porque não sofrera o processo de purificação através das cerimônias fúnebres; a alma era então condenada a errar sobre a superfície da terra, não encontrando repouso.

Esta crença explica a importância dada à sepultura, aos cuidados com os túmulos e, sobretudo, às oferendas de alimentos, de apetrechos e de armas usadas em vida pelos mortos, colocados junto das tumbas. Pensava-se que as almas se distraiam nos jardins contruídos em volta do túmulo e com os jogos fúnebres. Havia em certas sepulturas um recinto destinado a banquetes fúnebres, um dos entretenimentos oferecidos aos mortos (Prieur, 1986, p. 39).

Tal concepção fazia com que o romano se preocupasse em reservar um lugar apropriado para sepultar os restos mortais cremados ou inumados, em sepulturas simples ou trabalhadas, em vala comum nos campos de batalha, em columbários, em urnas e sarcófagos, e em mausoléus. Cada família se encarregava de assegurar uma sepultura conveniente ao parente morto. Era este um dos deveres do cidadão. Castigo mais grave do que a própria morte era a privação da sepultura. Quanto aos muitos mortos cujos corpos não puderam ser encontrados, havia um rito fúnebre substitutivo: preparava-se uma sepultura vazia e chamava-se três vezes o nome do defunto, convidando sua alma para sua nova morada (Prieur, 1986, p. 17).

Com a morte de César, inicia-se a honra até então reservada aos homens que já tinham obtido o triunfo: a do chefe de Estado ter sua sepultura preparada no interior da cidade. As circunstâncias da sua morte nos Idos de Março foram tão dramáticas que o povo lhe ergueu um templo espontaneamente (Suet. Iul. 84,1). Segundo Suetônio, durante os jogos consagrados à memória de César, surgiu um cometa que brilhou durante sete dias seguidos. Acreditou-se ser a alma de César admitida nos céus (Suet. $I u l .88,2$ ). Entre as honras conferidas a César está a sua divinização, o direito de se tornar um deus após a morte, considerado legítimo pelos soberanos absolutos. É de origem helênica e faz parte do poder totalitário (Taylor, 1975, p.1).Como a religião politeísta dos romanos admitia facilmente novos deuses, a divinização, consecratio, foi introduzida principalmente para atribuir ao sucessor do imperador morto a glória de ser diui filius, acrescentando-lhe uma auréola mágica necessária para a preservação do modelo de imperador (Grimal, 1981, p. 79). César morreu em 44 a.C. e a sua consagração foi-lhe conferida a partir de 42 a.C.

Augusto, o primeiro imperador, morreu em 14 d.C. Antes, a partir de 28 a.C., mandara edificar para si e sua família um mausoléu no Campo de Marte. A finalidade de um mausoléu é manter viva a memória do morto e fazer toda sua gente participar de sua glória. O mausoléu de Augusto, uma construção em forma de um círculo fechado em cima, com 87 metros de diâmetro e 45 metros de altura, era constituído, no seu interior, de anéis concêntricos que circundavam o espaço central em forma de círculo, reservado para o salão funerário e para a estátua do imperador. No interior destes círculos foram depositadas as urnas do imperador, de seus parentes próximos e de amigos chegados. Atrás está o bosque sagrado (Prieur, 1986, p. 92).

Para os funerais de Augusto, o senado decretou que o cortejo fúnebre passasse pela Porta Triunfal. Na frente desfilaram a estátua da Vitória, a seguir os troféus que o imperador havia depositado na cúria, os editais com os nomes das nações que ele havia submetido e duas imagens do imperador, tendo o cortejo fúnebre a solenidade de um triunfo (Suet. Aug. 50,2-3).

Circunstâncias, entretanto, passaram a modificar os ritos. É relevante notar que o senado tenha concedido a Augusto a honra de ser divinizado após um período de um mês de sua morte (Griffin, 1976. p. 129), a Cláudio, todavia, foi-lhe concedida tal honra logo após sua morte (Tac. 
Ann. XII,69,3). Interessa verificar analogias entre as homenagens póstumas prestadas tanto a um como a outro imperador.

Se, de um lado, Augusto deu início à preservação da memória de um soberano morto por meio da consecratio, de outro lado, não deixa de ser estranha a obra intitulada Apocolocintose, de Sêneca, a única sátira que escreveu, exatamente pela irreverência com que a morte do imperador Cláudio é tratada. Mesmo que não se saiba com certeza quando foi escrita, fiquemos com a hipótese mais provável, a de ter sido elaborada imediatamente após a morte de Cláudio (Grimal, 1976, p. 108), uma vez que seria a ocasião adequada para demolir a imagem de Cláudio.

A essência da sátira é ser um ataque literário. Entre as definições da sátira, convém lembrar a de Diomedes, (Keilli, 1857, p. 485):

Satura dicitur carmen apud Romanos nunc quidem maledicum et ad carpenda hominum uitia archaeae comoediae charactere compositum, quale scripserunt Lucilius et Horatios et Persius. (Entre os romanos, afirma-se que sátira é, na verdade, falar mal e é composta, segundo o caráter da comédia antiga, para censurar os vícios dos homens, tal como escreveram Lucílio, Horácio e Pérsio)

Cultivou-se este gênero em Roma aproveitando-se o gosto do romano pelo emprego do humor no maledicere, na censura e na crítica. Ainda segundo Diomedes (Keilii, 1857, p.485-6), o nome satura provém ou do nome satura que se atribuía a uma bandeja repleta das mais variadas frutas, que os antigos romanos destinavam a oferendas de caráter religioso, (siue satura a lance quae referta uariis multisque primitiis in sacro apud priscos dis inferebatur et a copia ac saturitate rei satura uocabatur), ou provém de um gênero em que se alternava prosa e verso como Varrão tentou fazer (siue a quodam genere farciminis, quod multis rebus refertum saturam dicit Varro uocitatum), ou provém da figura despudorada, burlesca e cômica dos sátiros, semelhantes aos bodes, tal como aparecem na literatura grega (quod similiter in hoc carmine ridiculae res pudendae que dicuntur, quae uelut a Satyris proferuntur et fiunt). Mesmo que não caiba aqui uma discussão sobre a origem da sátira, vale lembrar a famosa observação de Quintiliano: satura tota nostra est, com o fim de ressaltar que a sátira se coaduna bem com o espírito romano, seja por demonstrar a sua capacidade crítica, seja por revelar a mordacidade de seu espírito.

Como seria a sátira de Sêneca?

Não muito distante da visão moderna de Northrop Frye: "A sátira requer pelo menos uma fantasia mínima, um conteúdo que o leitor reconhece como grotesco, e pelo menos um padrão moral implícito, sendo o último essencial, numa atitude combativa, para a experiência" (Frye, 1957, p. 220). A Apocolocintose preenche tais requisitos. A sátira nos faz acompanhar a trajetória fantástica seguida pela alma de Cláudio, após o desenlace, em uma série de eventos que se realizam em localizações distintas. De acordo com estas e as passagens que a alma percorre, pode-se dividir as fases da sátira $\mathrm{em}^{2}$ :

Introdução Histórica (paródia) (I,I - I,3),

1. in terris (II, - IV,3),

2. in caelo $(\mathrm{V}, \mathrm{I}-\mathrm{XI}, 6)$,

3. ad Inferos (a caminho do inferno, XII, - XII,3),

4. in Inferiis (XIII, - XV,2).

A Introdução Histórica começa com uma curiosidade. Conforme Rosario Cortés (Cortés, 1986, p. 130 e ss.), fornece o assunto, a data e o local em que os eventos ocorreram como o faria uma introdução de tratado de Hitória. Se, entretanto, os acontecimentos têm dia e mês datados com precisão, já o ano não é mencionado e a informação sobre a local da ação, in caelo, remetenos, de imediato, para uma incongriência não compatível com obras históricas, uma vez que a função do historiador é expôr fatos verdadeiros. Sêneca afirma logo a seguir que tudo será narrado sem ressentimentos ou favorecimentos (Nihil nec offensae nec gratiae dabitur, I,l) tal 
como se emprega normalmente na historiografia. Ora, a nossa atenção é dirigida para aquele limite que fica entre ofalsum/uerum permitido em uma sátira, contaminado por informações que Sêneca deveria conhecer melhor que muitos na qualidade de preceptor de Nero. É muito provável que tenha tido conhecimento das circunstâncias reais da morte de Cláudio e das razões pelas quais a hora verdadeira do desenlace fora postergada. Conivente ou não, deve ter percebido os preparativos que foram feitos para Nero assumir o poder. As alusões são óbvias demais, por exemplo:

II,l: Claudium animum agere coepit, nec inuenire exitum poterat (Cláudio começou a preparar a alma para a partida, mas não conseguia encontrar a saída).

IV,2: Et ille quidem animam ebuliit, et ex eo desiit uiuere uiderit. (Na verdade ele solta a alma, a partir daquele momento deixou de parecer vivo).

Esta última observação aponta para o fato de que comediantes faziam uma representação teatral para um Cláudio reclinado em almofadas e, provavelmente, já morto. (Suet. Claud. 45,1).

Estas referências quanto à protelação do desenlace têm o mérito de revolver fatos históricos, como se patenteia no diálogo entre Mercúrio e Cloto, uma das Parcas, em que Mercúrio pede para que enfim se deixe Cláudio morrer, enquanto Cloto quer prolongar-lhe um pouco mais a vida:

III,3: Sed Clotho: "Ego, Mehercules, inquit, pusillum temporis adicere illi uolebam. (Mas Cloto responde: "Eu, por Hércules, gostaria de acrescentar-lhe um pouquinho de tempQ").

O fato das ações das fases 2, 3 e 4 terem como personagem principal um "herói" morto fecha algumas possibilidades e abre outras. De um lado, a personagem, não estando mais entre os vivos, não necessita ser elaborada com características de homo patiens, nem ter sentimentos. De outro lado, os traços marcantes de seu desempenho na terra estão a serviço da composição satírica. Sua figura é trabalhada sem grandes requintes e seu desempenho irá restringir somente ao que interessa considerando a finalidade da obra.

Esta trajetória é exatamente inversa à elevação que se pretende com a divinização de um soberano. Aliás a própria trama é montada no sentido de diminuir a dimensão do imperador Cláudio, por essa razão as cenas próprias da Épica, assembléia dos deuses, intervenção de deuses, a descida aos Infernos, são sumárias. Trata-se de degradar a figura do soberano morto. Para esta finalidade, aponta Rosario Cortés (Cortés, 1986, p. 207 e ss.), Sêneca se serve de certos recursos: o concilium deorum terá as características de uma sessão do senado romano. Vozes favoráveis são pouquíssimas: a de Hércules e a de uma deusa menor, a Febre. Mesmo Hércules não se apresenta como o grande herói, sua figura é diminuída, pois seu primeiro encontro com Cláudio, ante as portas do Olimpo, fá-lo recuar, pensando estar diante de um novo monstro e de um décimo terceiro trabalho a realizar. A última intervenção divina, e decisória, é a de Augusto, que, ríspida e definitivamente, sentencia o destino de Cláudio: deve ser banido do céu (XI,5). Clara alusão à maneira sucinta como o imperador morto presidia os julgamentos em Roma. A descida para os Infernos é abrupta, prestando-se para mostrar o soberano, maravilhado, ante a visão de seu próprio funeral. A narração acelera o ritmo. O inferno é descrito sumariamente, despojado de qualquer magicidade, a começar pela visão de Cérbero que apenas evoca no imperador a lembrança de sua cachorrinha branca. Ademais, Cláudio é recepcionado sem nenhuma reverência protocolar por seu liberto Narciso com uma pergunta desprovida de qualquer cortesia (Cortés, 1986, p. 263):

XIII,2: “Quid di ad homines?” (O que os deuses querem junto aos homens?).

Para concluir, a sátira se serve de outro iudicium do imperador, julgamento este mais sumário ainda, porquanto, diante das acusações, ninguém se digna a levantar-se para defendê-lo. 
A condenação final, degradante, é proferida pelo juíz de além-túmulo Éaco, que sentenciou não restar ao soberano outra coisa a fazer a não ser jogar dados com um copo sem fundo por toda a eternidade (alusão a uma preferência manifestada por Cláudio em vida).

Como explicar o fato de Sêneca limitar as açòes da Apocolocintose ao mundo das sombras, após a morte do imperador?

Mesmo que não se possa afirmar haver nesta sátira um retrato fiel de Roma, uma vez que Cláudio não era objeto de repúdio em todas as classes da sociedade romana, sendo repudiado só em determinados segmentos, há na obra, todavia, a idéia de que fundamentalmente se trata de crítica e de maledicere. As alusões, os exageros e as amplificações fornecem elementos que justificam pensar que Cláudio é "des-mitificado" e "des-divinizado". Esta é, em síntese,a conclusão a que Rosario Cortés chegou (Cortés, 1986, p. 283 e ss.): sua imagem será desfeita, gradualmente, de cima para baixo.

De fato, o processo de desmonte da personagem do imperador Cláudio é de cunho histórico, político e religioso. Desenvolve-se à medida que o "herói" percorre um caminho às avessas da divinização. Aqui,

o "herói" não morre: sua alma procura saída do corpo;

o "herói" não é herói: é uma alma;

no céu, os deuses tiram do "herói" sua condição divina, conferida pelos homens na terra;

no inferno, o "herói" perde sua condição de "homem livre", e em clara alusão à sua preferência pelos amigos libertos, finaliza como um cognitio de um liberto qualquer.

Para concluir, pode-se observar que Roma conheceu sátiras e ironias. Porém o que mais surpreende na Apocolocintose é a crítica a soberano recém-falecido. Se, como vimos acima, era praxe homenajear solenemente os mortos, por que Sêneca a escreveu?

A sátira constitui-se de três pressupostos básicos: a) fatos históricos mais ou menos confiáveis; b) crítica através do ridiculum, maledicere, censura (notare) etc; c) necessidade histórica.

Por ocasião da morte de Augusto, o imperador fora divinizado e as honras prestadas ao soberano morto foram todas cumpridas. Seus restos foram levados ao Mausoléu onde já estavam diversos membros de sua família. Embora não tivesse descendentes diretos em condições para deixar no poder, deu legitimidade a Tibério e sua herança, o caráter divino do imperador, teve continuidade. Augusto, de um lado, propugnava a restauração da religião romana e, de outro, pretendia imprimir novos rumos ao Império com vistas a sua preservação, mas impondo um modelo diárquico de governo, em que atuavam senado e imperador.

Ora, não era diferente a pretensão de Sêneca, que estava muito perto do poder como preceptor de Nero e, a seguir, como amicus principis.

Cláudio também recebeu as devidas homenagens fúnebres. Ao contrário de Augusto, deixou descendentes diretos, principalmente Britânico, um herdeiro masculino, eventualmente adequado para assumir o poder, que muito rapidamente foi preterido por manobras de Agripina a favor de seu próprio filho Nero, convenientemente adotado por Cláudio.

Aparentemente a sátira foi elaborada logo após a morte do soberano. Em seus diferentes aspectos a obra, mesmo com as lacunas que apresenta, organiza-se com muitos recursos satíricos, alguns fáceis, outros sutis para a intelecção moderna. Mas um aspecto fica evidente: como a personagem principal é um morto, o ridículo com que é revestido na sátira, não preservará sua memória. Nesse processo, o poder sobrenatural do soberano é simbolicamente desfeito. Ademais, mostrar o grotesco desenlace de Cláudio, é querer deliberadamente atingi-lo em um dos sentimentos mais naturais do romano em relação à morte, pois reverência e cumprimento dos ritos fúnebre que se iniciam imediatamente logo após a morte é um dos alicerces da pietas romana.

Há muitas maneiras de criticar. Destruir, entretanto, a imagem de Cláudio, no momento de transição do poder para o sucessor, Nero, aproxima-se de uma tentativa de aniquilar não propri- 
amente a figura do falecido, mas antes o modelo de soberano que o claudianismo incorporara: uma tirania de caráter absoluto apoiada sobre libertos. Concentrar a crítica, sobretudo, na consecratio, homenagem de caráter tanto político quanto religioso é, antes de mais nada, ousar definir uma posição política, fato que confere um caráter programático a esta sátira. No caso, dirigir a mira do ataque para o poder político é tentar despertar as consciências individuais contra o tipo de organização estatal que Cláudio incorporara. Esta seria a herança política à qual Sêneca se opunha.

Havia muitos deuses no panteão romano. Naquele momento histórico-político não havia necessidade de erguer mais um altar, muito menos para o divino Cláudio. Parece que disso se encarregou a Apocolocintose.

\section{Notas}

1. O presente artigo é devedor da tese de Rosario Cortés.

2. Rosario Cortés divide a sátira em seis partes I. Título, proemio y marco temporal; II. Muerte de Claudio y alabanza de Nerón; III. A las puertas del Olimpo; IV. Concilium Deorum; V. Viaje a los infiernos: funeral de Claudio; VI. Claudio en los infiernos (Cortés, 1986). A divisão simplificada, em quatro partes, precedidas por uma introdução de caráter histórico, serve ao propósito do presente comentário.

\section{Referências Bibliográficas}

CORTÉS, Rosario. Teoría de la sátira. Análisis de Apocolocyntosis de Séneca. Cáceres: Universidad de Extremadura, 1986.

FRYE, Northrop. Anatomia de crítica. Trad. P. E. da Silva Ramos. São Paulo: Cultrix, 1957.

GRIFFIN, Miriam. T. Seneca, a philosopher in politics. Oxford: At the Clarendon Press, 1976.

GRIMAL, Pierre. La civilisation romaine. Paris: Flammarion, 1981.

GRIMAL, Pierre. Sénèque, ou la consciende de l'Empire. 2 ed., Paris: "Les Belles Lettres”, 1976.

KEILLI, H. Grammatici Latini. Diomedes, v.I. Lipsiae: In aedibus B.G. Teubneri, 1857.

PRIEUR, Jean. La mort dans l'antiquité romaine. Ouest France, 1986.

TAYLOR, Lily Ross. The divinity of the Roman Emperor. New York: Arno Press, 1975.

BRAREN, Ingeborg. Le Mausolée d'Auguste et l'Apocolocynthosis de Sénèque. Classica, São Paulo, 7/8: 165-170, 1994/1995.

RESUMÉ: Auguste construisit pour lui-même et les membres de sa famille un mausolée, afin que soient rendus à leurs dépouilles les honneurs funèbres qui leur étaient dus. A l'héritage qu'il laissa, appartenait le modèle politique du souverain qui se perpétua avec l'Empire Romain. Son souvenir a subsisté et son mausolée existe toujours. Au contraire, la mort de l'empereur Claude, comme elle est traitée dans l'Apolocynthosis de Sénèque, offre l'exemple d'un "héros", mort, dont le rôle se situe sur une trajectoire post-mortem, un parcours exactement inverse de celui de la consecratio, hommage de divinisation conferé à certains empereurs et qui lui avait été rendu, puisque dans la satire il descend du ciel aux enfers.

MOTS CLÉ: Apocolocynthosis, Sénèque, Empereur Claude, Consecratio, Auguste. 